\title{
PRODUÇÕES CURRICULARES NO ENSINO DE HISTÓRIA: desafios do "contemporâneo"
}

\author{
Ana Maria Monteiro \\ Thays Merolla Piubel
}

\section{Resumo}

O artigo tem por objetivo propor uma discussão sobre questões de pesquisa em ensino de História considerando contribuições de Giorgio Agamben (2007) sobre o contemporâneo, não como tempo histórico, mas como um marcador existencial no qual a percepção, disjunção de zonas obscuras gera inquietações e estranhamentos. A abordagem de temas sensíveis no ensino de História é objeto de problematização dos sentidos de ensinar/aprender/pesquisar temáticas envolvidas em silêncios, preconceitos e negacionismos nos currículos prescritos e praticados. A análise focaliza o currículo mínimo do estado do Rio de Janeiro (2012) e entrevistas com professores. Entre as conclusões, destaca-se a importância dos docentes em produzir narrativas históricas, realizando o enfrentamento de discursos negacionistas e dialogando com temas silenciados nos currículos prescritos, possibilitando a emergência da diferença.

Palavras-chave: ensino de história; contemporâneo; currículo; narrativa histórica; temas sensíveis

\section{CURRICULAR PRODUCTIONS IN HISTORY TEACHING: issues from the "contemporary"}

\begin{abstract}
The article aims to propose a discussion on research issues in History teaching considering Giorgio Agamben's (2007) contributions on the contemporary, not as historical time, but as an existential marker in which perception, disjunction of obscure areas generates concerns and strangeness. The approach of sensitive themes in the History teaching is the object of questioning the meanings of teaching/learning/researching themes involved in silences, prejudices and negationism in the prescribed and practiced curriculum. The analysis focuses on the minimum curriculum of the state of Rio de Janeiro (2012) and interviews with teachers. Among the conclusions, we highlight the importance of teachers in producing historical narratives, dealing with negationist discourses and dialoguing with silenced themes in the prescribed curriculum, enabling the emergence of difference.
\end{abstract}

Keywords: history teaching; contemporary; curriculum; historical narrative; sensitive themes

\section{PRODUCCIONES CURRICULARES EN ENSEÑANZA DE LA HISTORIA: desafíos en lo "contemporáneo"}

\section{Resumen}

El artículo tiene como objetivo proponer una discusión sobre cuestiones de investigación en la enseñanza de la historia considerando las contribuciones de Giorgio Agamben (2007) sobre lo contemporáneo, no como tiempo histórico, sino como un marcador existencial en el que la percepción, la disyunción de áreas oscuras genera preocupaciones y extrañeza. El abordaje de temas sensibles en la enseñanza de la Historia es objeto de cuestionar los significados de los temas de enseñanza/aprendizaje/investigación envueltos en silencios, prejuicios y negacionismos en los currículos prescritos y practicados. El análisis se centra en el currículo mínimo del estado de Río de Janeiro (2012) y entrevistas a docentes. Entre las conclusiones, 
destacamos la importancia de los docentes en la producción de narrativas históricas, abordar los discursos negacionistas y dialogar con temas silenciados en los currículos prescritos, posibilitando la emergencia de la diferencia.

Palabras clave: enseñanza de la historia; contemporáneo; currículo; narrativa histórica; temas sensibles

\section{INTRODUÇÃO}

O passado não reconhece o seu lugar: está sempre presente...

(Mario Quintana)

Educação, educar - ex-ducere, conduzir "para fora", fora de si mesmo e conhecer, enfrentar, desafiar o mundo, vencer o egocentrismo, o reducionismo isolacionista e aprender que nos constituímos sujeitos nas relações com o "outro", que somos diferentes e a diferença nos constitui. O contemporâneo, o mesmo tempo, tempo concomitante, tempo presente, o aqui e agora numa relação que adere e que, ao mesmo tempo, possibilita tomar distância, através de uma dissociação, de um certo anacronismo (AGAMBEN, 2007, p. 59). Brasil, um país que se apresenta como uma nação una, mas constituída por muitas nações, grupos, "tribos", pessoas em sua diversidade de potência criativa transformadora. E país no qual vivemos, no contemporâneo, tempos difíceis, estranhos, sob ameaça do "novo coronavírus" que nos faz pensar que estamos dissociados de nós mesmos e de nossos projetos, crenças, ética.

Perplexos e indignados temos assistido, já há alguns anos, professores e professoras serem desqualificados, questionados e criminalizados por alguns e, ao mesmo tempo, serem reconhecidos como profissionais indispensáveis para o desenvolvimento de educação democrática e formadora de sujeitos com autonomia no pensar e deliberar sobre suas vidas privadas e comunitárias. Escola, docência, formação de professores, conhecimentos, educação - estão postos em questão, de forma nunca vista, o que exige reflexões e posicionamentos.

A escola, os professores e o ensino ainda são necessários? Quais conhecimentos importa ensinar/aprender? E a disciplina História, intrinsecamente implicada com o social, o cultural, o político, a memória, ainda é necessária de ser ensinada? Por quê? Para que? E o fazer pesquisa? Onde e como produzir conhecimentos novos, revisitar produções em tempos de cortes governamentais, redução de investimentos em educação, na cultura e na investigação científica? Como fazer pesquisas em ensino de História no contemporâneo, campo político por excelência, e com o distanciamento necessário para melhor compreendê-lo?

Certamente vivemos tempos estranhos, que apresentam retrocessos do ponto de vista cultural, social, político, e com graves riscos à democracia como não imaginávamos pudesse acontecer no Brasil após o fim do regime militar e o período de redemocratização. Princípios democráticos que orientaram e orientam o nosso trabalho docente, na educação básica e superior, são atacados, desqualificados e desmoralizados por autoridades governamentais da esfera do executivo e do legislativo, e, em alguns casos, do judiciário. Princípios que considerávamos universalizados e de compreensão geral pela população brasileira, descobrimos que são questionados, negados, alvos de escárnio e de distorções em discursos de ódio que circulam nas redes sociais.

E quando nos questionamos, perguntando como isso é/foi possível, vem à lembrança, por exemplo, os discursos ultra conservadores, entre eles os de algumas religiões, que negam peremptoriamente as contribuições científicas e disseminam informações falsas em diferentes espaços e meios de comunicação. Mas esta resposta explica tudo o que está acontecendo? Certamente que não. Como foi possível o desenvolvimento deste processo/retrocesso? 
Professores de História se perguntam em que falharam, mas acreditamos que não podemos assumir esta culpa em um processo social de tal amplitude e agravado de forma inesperada e insuspeitada em meio à pandemia do Covid-19.

Formados no contexto do regime moderno de historicidade, muitos ainda mantêm a crença no futuro como "lugar" de um devir inexorável da história, que carregaria em si o progresso para os povos. E a educação, mais especificamente a educação escolar republicana, nesse contexto, teria um papel estratégico ao disponibilizar às crianças, adolescentes e jovens os conhecimentos produzidos pela ciência e adequados para a aprendizagem desses "cidadãos" em formação. "Educar através da instrução" tornou-se um objetivo fundamental das nações que se constituíram na modernidade ocidental, devidamente ancoradas economicamente no desenvolvimento capitalista em expansão.

Face ao exposto, a perplexidade mencionada no início do texto é expressão de uma visão ingênua sobre a história, o social, o político e cultural? Estes aspectos não teriam relação com a condição pós-moderna que caracteriza as sociedades contemporâneas nas quais não reconhecemos mais um telos do progresso e bem-estar social, mas disputas em torno de regimes de verdade e de hegemonia por diferentes grupos e seus projetos políticos?

Ao mesmo tempo, como lidar com questões que nos desafiam no tempo presente, quando um "passado" que considerávamos passado, emerge com força, presença reativada, resgatando/afirmando sentidos sobre o mundo, a cidadania, as identidades, a diversidade em perspectivas já discutidas, questionadas, negadas. Como agir para se contrapor, lutar contra ideias que reafirmam a continuidade de um mundo baseado na desigualdade, nos preconceitos, no racismo, no fatalismo, no anti-cientificismo? Como desenvolver uma educação que afirme princípios e práticas democráticas e constitua sujeitos livres e responsáveis para um futuro humano (BIESTA, 2013)?

E, mais especificamente, no ensino de História: o que abordar, quando as informações são rapidamente encontradas em aplicativos buscadores na internet? Como promover um interesse pela compreensão sobre a historicidade do social nas novas gerações? Como argumentar frente a afirmações falsas, distorcidas ou a dogmas de cunho religioso? Como questionar verdades estabelecidas sem substituí-las por outras verdades fechadas/doutrinárias? Como, ao mesmo tempo, questionar versões sobre nossa história nas quais ainda identificamos um predomínio de perspectiva "colonizada", com dificuldades para reconhecer o protagonismo de afro-brasileiros e indígenas, escravizados ou não, nas múltiplas temporalidades?

Como historiadores/professores contemporâneos aos fatos mencionados, propomos uma reflexão, um pensar mais cuidadoso/cauteloso em diálogo com autores que possam auxiliar a tentativa de análise desta conjuntura que apresenta tantas contradições e disputas de narrativas sobre a história, a nação, o seu passado e o seu futuro.

Por um lado, discutir questões relacionadas à temporalidade pode contribuir para a melhor compreensão de um presente complexo no qual o passado parece não passar, se constituindo enquanto trauma para muitos dos atores envolvidos, envolvendo os chamados "temas sensíveis" ou "controversos", os quais serão debatidos na terceira seção do artigo.

Por outro lado, consideramos importante focalizar a narrativa, que se configura como forma discursiva constituinte do conhecimento historiográfico e histórico escolar, e que nas disputas entre os regimes de verdade apresente argumentos plausíveis que venham a se contrapor e questionar verdades estabelecidas, distorções e suscitar o raciocínio histórico eticamente comprometido com o fazer historiográfico e com princípios democráticos.

Pensar uma educação democrática não é um ato de vontade, que se basta em si mesmo. Implica pensar em como agir com responsabilidade frente ao humano, em relação com as múltiplas 
diferenças que nos constituem como sujeitos. E uma educação que se deseja democrática, atravessada pelo currículo, em suas múltiplas dimensões, precisa ser problematizada, o que é realizado neste artigo, a partir das contribuições teóricas do campo do currículo mobilizadas em pesquisa, na análise de discursos sobre currículos produzidos por professores e daqueles fixados em documentos curriculares.

Nesse sentido, em acordo com Paraíso (2010), entendemos que o currículo é diferença em si, pois é o espaço da multiplicidade, do indeterminado, de produção da vida e seus sentidos no estar com o outro.

Um currículo é diferença por natureza; é pura diferença; é diferença em si. Afinal, é um território de multiplicidades de todos os tipos, de disseminação de saberes diversos, de encontros "variados", de composições "caóticas", de disseminações "perigosas", de contágios "incontroláveis", de acontecimentos "insuspeitados". Um currículo é, por natureza, rizomático, porque é território de proliferação de sentidos e multiplicação de significados. Apesar de todos os poderes que fazem o controle, demarcam as áreas e opinam sobre como evitar a desorganização em um currículo e que demandam sua formatação, tudo vaza e escapa. (PARAÍSO, 2010, p. 588)

Dirigir o olhar a este "[...] território de proliferação de sentidos" nos desafia a pensar também em como produzir conhecimento, realizar pesquisas com sujeitos, outros, não sobre outros, ouvindo em uma escuta sensível suas narrativas que, produzidas ao serem narradas, dão continuidade ao processo de constituição de subjetividades do pesquisador e dos pesquisados.

$\mathrm{Na}$ primeira seção do artigo discutimos a questão da temporalidade a partir do conceito de "contemporâneo" (AGAMBEN, 2007) na abordagem dos desafios, fissuras e questões postas no ensino de História. $\mathrm{Na}$ segunda seção do artigo, focalizamos referências a esses temas em documentos curriculares do estado do Rio de Janeiro na década 2010, buscando identificar zonas obscuras, silenciamentos e a abordagem da diferença no currículo. $\mathrm{Na}$ terceira e última seção refletimos acerca da emergência da diferença na prática curricular de História a partir de temas sensíveis, os quais geram controvérsias dentro e fora da escola ao fazer emergir a dor e as memórias de grupos historicamente marginalizados, tendo por base narrativas de professores de História.

\section{FAZER/PESQUISAR HISTÓRIA NO CONTEMPORÂNEO}

A história se faz a partir do e para o presente, os historiadores dos Annales nos ensinaram... E dessa constatação, os estudos realizados ao longo do século XX sobre a teoria da História nos permitem afirmar que:

Ao contrário do que defendiam os historiadores vinculados às escolas metódicas, o passado não faz sentido em si mesmo e não está desconectado do contemporâneo. O passado não possui uma verdade fechada, mas está sujeito à permanente reelaboração de sua inteligibilidade a partir das questões que lhe são formuladas a partir das preocupações, das condições históricas do presente em que é interrogado, estudado, analisado, ensinado. A história produzirá versões distintas para o passado, tratando-o sob novas perspectivas, dando-lhe novas abordagens, à medida que as próprias transformações históricas assim requeiram. (ALBUQUERQUE JR., 2012, p. 30)

Esse entendimento sobre o fazer historiográfico que já nos parece consensual entre os historiadores neste final da segunda década do século XXI, ainda apresenta desafios importantes 
no que se refere ao ensino da História na educação básica. Entendida por alguns como expressão de um relativismo paralisante e descompromissado, em que tudo vale, podemos, por outro lado, reconhecer nesta perspectiva, possibilidades de compreensão e busca de superação de contextos marcados por injustiças e desigualdades sociais. Do ponto de vista do ensino, essa compreensão carrega muitos desafios. Confrontados com a afirmação de que "[...] o passado não está dado, narrado em versão que expressa uma verdade fechada e acabada", estudantes ficam desestabilizados e inseguros e muitos, descrentes em relação a um conhecimento que não oferece certezas da mesma forma que as crenças religiosas e mitos.

Como trabalhar em perspectiva que possibilite o desenvolvimento do raciocínio histórico e que tem como referente básico a abordagem problematizadora de verdades estabelecidas que podem nos oprimir, sufocar em redes de poderes hierarquizantes e reprodutores de desigualdades sociais? Desestabilizador, este movimento carrega, no entanto, grande potencial libertador e que possibilita a formação de sujeitos livres e com melhor compreensão sobre a sua inserção no social.

Esta forma de abordagem ao longo de aulas referenciadas em procedimentos metodológicos do fazer historiográfico, e considerando a diferença de trabalho com estudantes da educação básica e com historiadores em formação, pode criar condições para o enfrentamento das disputas de narrativas em curso com mais segurança e sustentada em contribuições da historiografia e dos estudos pedagógicos.

Em contexto de versões que buscam confundir, desqualificar memórias e desestabilizar princípios democráticos, mais do que nunca a compreensão de que a história se faz a partir do presente representa uma ferramenta teórica e política estratégica. A abordagem do passado a partir de questões emergentes abre a possibilidade para pensar passados outros, com outros "enredos" e outros personagens e relações de poder, e viabilizar a compreensão da historicidade do social e de uma noção de tempo que vá além daquilo que se define e se pensa como presente e passado estabilizados.

A história serve para que possamos realizar no plano do conhecimento, do pensamento, do imaginário, da memória, aquilo que não podemos fazer no plano da realidade e da empiria: sair do presente, ausentar-nos dessa temporalidade que nos cerca, olhar este tempo de fora e ter com ele uma relação de distanciamento, estranhamento, ter, dele, uma visão perspectiva. (ALBUQUERQUE JR, 2012, p. 30)

Ou seja, a libertação de um cotidiano que muitas vezes nos aprisiona ao se apresentar como única opção de vida possível com suas limitações, imposições e discriminações. Um descentramento do presente que possibilita desconstruir suas estabilidades dadas como naturais, desvelando o caráter histórico de sua constituição.

Estas reflexões de Albuquerque Jr. nos remetem às contribuições de Giorgio Agamben (2007) sobre "o contemporâneo" que nos auxiliam na construção de possibilidades de compreensão em perspectiva crítica dos processos em tela. Ao discutir o que é o contemporâneo, aquilo que existe "ao mesmo tempo em que", o autor inicia uma problematização deste conceito baseando-se em Nietzsche, "[...] que situa a sua exigência de atualidade, a sua contemporaneidade em relação ao presente numa desconexão e numa dissociação.” (AGAMBEN, 2007, p. 58)

Pertence verdadeiramente ao seu tempo, é verdadeiramente contemporâneo, aquele que não coincide perfeitamente com este, e nem está adequado às suas pretensões e é, portanto, nesse sentido, inatual; mas exatamente por isso, exatamente através desse deslocamento e desse anacronismo, ele é capaz mais do 
que os outros, de perceber e apreender o seu tempo. (AGAMBEN, 2007, p. 5859)

Continuando seu raciocínio, Agamben (2007, p. 59) afirma que:

[...] aqueles que coincidem muito plenamente com a época, que em todos os aspectos a esta aderem perfeitamente, não são contemporâneos porque, exatamente por isso, não conseguem vê-la, não conseguem manter um olhar atento sobre ela.

O alerta deste autor nos parece relevante, pois contribui para que possamos aprofundar a compreensão sobre a complexidade do tempo presente, considerando que o contemporâneo implica "pensar em desconexão". Com distanciamento, em perspectiva, para então sermos capazes de problematizar as zonas obscuras, sombrias. De acordo com Agamben (2007, p. 62), uma segunda definição de contemporâneo refere-se à

[...] aquele que mantém fixo o olhar no seu tempo, para nele perceber não as luzes, mas o escuro. Não o escuro como privacidade, mas como obscuro, que se nega a visão imediata, que torna necessário insistir, investigar em busca da luz que não podemos alcançar, mas está em busca de nós: “já, muito cedo, muito tarde, ainda não.

O passado que buscamos compreender a partir da imaginação e referenciada em fontes, nos permite, por outro lado, nesse recuo do tempo, ter uma visão diferenciada de nosso presente, em novas perspectivas. Presente, passado e futuro, temporalidades que se encontram na contemporaneidade, que congrega "[...] espaço de experiências e horizonte de expectativas" (KOSELLECK, 2006) e na qual distanciamento e desconexão permitem pôr em questão verdades estabelecidas e pensar outros passados e futuros, horizontes possíveis.

Complexa relação entre as temporalidades para as quais não temos dado a devida atenção em nossas aulas de História. Analisando narrativas construídas com base em regimes de verdade em disputa, a abordagem das questões temporais e do fazer historiográfico pode abrir caminhos com nossos alunos para o desenvolvimento de raciocínio histórico ética e politicamente fundamentado.

Romper com a tradição da história do Brasil em sua versão construída ao longo do século XIX e que tinha por objetivo afirmar a continuidade da obra de estabelecimento da civilização ocidental nos trópicos (GUIMARÃES, 1988), ainda se apresenta como desafio a ser enfrentado. De atrasados, inimigos, selvagens passar ao reconhecimento de negros e índios como sujeitos em luta e defesa de suas terras, cultura, religiões, de seus corpos, não como conteúdos adicionais a serem incorporados à versão canônica estabilizada, mas enquanto presença em um passado "reinventado" (ALBUQUERQUE JR., 2007) com base nos estudos e pesquisas historiográficos recentes. Esta perspectiva, certamente, poderá contribuir para o enfrentamento de temas sensíveis, entre eles o racismo, neste contemporâneo confuso, expressão de interesses e disputas por hegemonia por meio de apagamento e/ou desqualificação de memórias e histórias.

Nesta seção do artigo buscamos refletir acerca do conceito de "contemporâneo" e suas relações com os desafios e possibilidades da problematização no aprender e ensinar História no tempo presente. Na seção seguinte, nos aproximamos do campo do currículo focalizando possíveis silenciamentos, obscuridades que permanecem no contemporâneo, sejam em documentos ou práticas, como operadores de memórias traumáticas que, atualizadas, aguçam sensibilidades na abordagem de temas sensíveis. 


\section{NARRATIVA HISTÓRICA ESCOLAR: SENTIDOS DE SUJEITOS, SABERES, PRÁTICAS}

Em nossas pesquisas temos investigado a argumentação dos professores sobre a mobilização, por eles realizada, dos saberes docentes em relação ao conhecimento histórico escolar produzido em aulas na educação básica (MONTEIRO, 2007a). Nesse sentido, tem sido possível confirmar a originalidade desta produção que articula referências dos conhecimentos historiográficos e pedagógicos com saberes dos alunos, dos professores, da cultura escolar, da história pública que circula nas diferentes mídias sociais, na sociedade de forma geral (MONTEIRO, 2015).

Espaço-tempo de fronteira cultural (MACEDO, 2006) demanda contribuições dos estudos e pesquisas da Historiografia/Teoria da História e da Pedagogia para sua análise e compreensão. Lugar de fronteira (MONTEIRO, 2007b; MONTEIRO, PENNA, 2011) que nos desafia ainda mais em contextos complexos como o que se configura em nossa realidade atual. Nesse sentido, estamos desenvolvendo pesquisa na qual buscamos investigar em perspectiva histórica (1985-2015) os currículos prescritos ${ }^{1}$ e praticados no Rio de Janeiro (cidade e estado) em sua dinâmica constitutiva que se apresenta na tensão entre tradições e inovações.

Embora muitos docentes não demonstrem interesse pelas propostas curriculares e afirmem que não as conhecem ou seguem, elas estão presentes de forma difusa nos diferentes documentos curriculares institucionais e aqueles produzidos pelos docentes a partir das interpretações, apropriações e leituras destes. Constitui-se em contexto discursivo no âmbito do qual atuam os docentes. Não estamos operando a partir do entendimento de que currículos prescritos são implementados ou negados, em perspectiva binária, disjuntiva, mas enquanto contexto discursivo produtor de sentidos sobre práticas.

Tendo por base as contribuições de Ball, Bowe e Gold (1992), nossa perspectiva possibilita considerar que as políticas curriculares são produzidas nos contextos de influências, de produção de textos e da prática. Os discursos que neles circulam produzem sentidos sobre o que/como/porque ensinar/aprender e são (re)elaborados, apropriados em fluxos contínuos transformadores. Nesse sentido, o que é fixado nos documentos oficiais induz e ao mesmo tempo expressa sentidos presentes no contexto educacional local/global.

Para a análise dos documentos, foram realizados estudos sobre o contexto político da redemocratização, as tendências pedagógicas hegemônicas e as propostas em tela, tendo por referência as contribuições de Foucault (FOUCAULT, 2000, p. 149-150) sobre o arquivo que orienta a constituição discursiva. A teorização foucaultiana sobre a emergência dos saberes, as camadas que compõem o discurso, as regras que orientam a enunciação têm se mostrado muito potentes para a compreensão do movimentos de inovação propostos e as tradições que se mantinham, organizando a produção discursiva sobre o que significava ensinar História.

Em tempos de reconstrução da democracia, nossa pesquisa focalizou tensões entre esforços realizados para a superação de narrativas canônicas da história do Brasil, construídas com base em perspectiva eurocêntrica e colonizada, e a estabilidade de certas tradições.

Quais sentidos foram atribuídos aos sujeitos, saberes e práticas nas narrativas sobre a história do Brasil?

Tendo por base as discussões sobre racismo, que entendemos ser um tema sensível na história do Brasil e que reverbera dentro e fora da sala de aula, realizamos uma análise do currículo

\footnotetext{
${ }^{1}$ Selecionamos propostas curriculares oficiais produzidas no âmbito da Secretaria Municipal de Educação da cidade do Rio de Janeiro e Secretaria de Estado da Educação do Rio de Janeiro no período em tela.
} 
mínimo (2012), documento curricular vigente no estado do Rio de Janeiro e que integra o arquivo da pesquisa. A partir dessa análise procuramos compreender qual o tratamento dado à essa temática neste documento curricular, o qual foi produzido no início da década de 2010, em um momento posterior à aprovação da Lei n. 11.645/08² no país.

O currículo mínimo da rede estadual do Rio de Janeiro para a disciplina História foi elaborado em 2011 e revisto no ano seguinte (2012), sendo adotado na rede no mesmo ano de sua revisão. É organizado a partir das categorias "conteúdos", para tratar dos conteúdos específicos da disciplina História e "habilidades e competências" em forma de objetivos a serem alcançados pelos estudantes.

No texto introdutório da proposta para a disciplina são explicitados alguns dos objetivos que guiaram a produção do texto curricular:

Na concepção deste Currículo Mínimo fizemos a opção de seguir uma ordem
cronológica, delimitada a partir dos grandes marcos reconhecidos, ou seja, Pré-
História, Antiga, Medieval, Moderna e Contemporânea. Dentro destes conteúdos
procurou-se integrar África, América, Ásia, Brasil e Europa. Essa escolha não
exclui, entretanto, a possibilidade de se trabalhar com eixos temáticos
permitindo, assim, a reflexão entre passado e atualidade de forma comparativa.
A partir dessa escolha a equipe de História inseriu nas diversas séries o ensino de
África, a questão indígena, os debates sobre a América Latina e as referentes às
perseguições de minorias - quer étnicas, culturais, religiosas ou sexuais. Não
pensamos somente em cumprir a legislação, mas, sobretudo, acreditamos que
estes são conteúdos essenciais para a formação do nosso educando e para a
sociedade. (RIO DE JANEIRO, 2012, p. 4)

A partir da citação acima e da análise da proposta curricular, entendemos que o currículo de História, apesar de apresentar a introdução de temáticas como a história da África - atendendo a Lei n. 11.645/08 - permanece preso a uma lógica quadripartite ${ }^{3}$ de se pensar a História, na qual a história da Europa é o fio condutor da história mundial.

Sobre a questão do racismo, que nos parece uma questão central de ser debatida nas escolas em uma perspectiva de compreender os desdobramentos históricos da escravidão para a população afro-brasileira no tempo presente, o currículo mínimo apresenta apenas uma citação do conceito no corpo do documento, na seguinte frase: "Desenvolver atitudes contrárias ao racismo, ao preconceito e qualquer forma de discriminação". (RIO DE JANEIRO, 2012, p. 10)

Essa "competência", curiosamente, não está relacionada a nenhum conteúdo histórico da história brasileira, mas no conteúdo para o $9^{\circ}$ ano do ensino fundamental denominado "Período entreguerras: crise econômica e social e nazifascismo", que se refere às décadas de 1920 e 1930 na Europa e nos Estados Unidos da América.

Ao analisar a questão do racismo neste documento curricular de História e evidenciar silenciamentos e obscuridades, podemos perceber que nos momentos de sua produção, no seu "contemporâneo", e que exploramos no sentido proposto por Agamben, a questão do racismo, constitutiva da realidade pretérita e presente no Brasil, que violenta, mata, exclui e silencia milhões de brasileiros cotidianamente, é apresentada de maneira esvaziada e objetificada no currículo.

\footnotetext{
2 A Lei n. 11.645/08 determina a obrigatoriedade do ensino da história e cultura africana, afro-brasileira e indígena na educação básica, em escolas públicas e privadas.

${ }^{3}$ História quadripartite é um modelo de divisão do ensino da História em quatro grandes blocos: História Antiga, História Medieval, História Moderna e História Contemporânea. Nesse modelo, fatos históricos determinados marcam o início e o fim de cada época, sendo a Europa o guia "natural” dos processos históricos. (MATOS, 2012, p. 55).
} 
Quando o passado de violência da escravidão e suas remanescências no tempo presente - como o racismo - não são definidos como estruturantes no currículo de História nas escolas brasileiras, como possibilitar a superação de visões preconceituosas e desumanizadoras sobre a população afro-brasileira e indígena no passado e no presente? Apagamentos da diferença no currículo gerando traumas e desigualdades.

Nesta seção buscamos dialogar com autores que pensam o currículo de uma maneira plural, seja como espaço-tempo de fronteira cultural ou produção em diferentes contextos de influência. Além disso, analisamos de que maneira o conceito de "racismo" foi apresentado no documento curricular de História vigente no estado do Rio de Janeiro, entendendo a importância do currículo prescrito enquanto expressão das tradições, demandas e disputas pela educação, em geral, e pelo ensino de História, especificamente, mas também a partir de suas zonas obscuras e silenciamentos. $\mathrm{Na}$ próxima seção procuramos refletir sobre a importância dos temas sensíveis no ensino de História, articulando com narrativas de professores de História sobre os desafios e estratégias para enfrentamento de narrativas negacionistas e excludentes, em um fazer curricular da/na prática docente.

\section{TEMAS SENSÍVEIS NA AULA DE HISTÓRIA: A (RE)EMERGÊNCIA DA DIFERENÇA}

E como fissurar a narrativa colonial da história brasileira presente nos currículos da disciplina História que apaga, violenta e desqualifica sujeitos, memórias, saberes? Uma das possibilidades é apostar no debate dos temas sensíveis na sala de aula, que busca fazer emergir os sujeitos e memórias historicamente marginalizados em uma articulação temporal passado/presente.

Os temas sensíveis ou controversos são questões que se relacionam com a violência física e/ou simbólica sofrida por grupos historicamente marginalizados, sendo, portanto, violações aos direitos humanos em diferentes contextos históricos. Dentre alguns exemplos desses temas sensíveis podemos citar a escravidão africana e indígena no continente americano, entre os séculos XVI e XIX, o Holocausto e as ditaduras civil-militares no Brasil e na América Latina, no século $\mathrm{XX}$.

Sobre os temas sensíveis, nos dizem Gil e Eugenio (2018, p. 143):

No Brasil, alguns temas sensíveis seguem na esteira das lutas de diferentes grupos
em busca de legitimidade para suas histórias e memórias, questionando a
homogeneização que marca a ideia de nação. Junto a isso, os grupos buscam
ampliar a representação política, e a luta por direitos faz emergir demandas
identitárias. Ou seja, é uma luta que reivindica lembrar, manter viva uma memória
e reparar o silêncio e as simplificações na narrativa histórica. Assim, a unidade
nacional tem sido questionada - não sem resistência - dando visibilidade à uma
sociedade que é multicultural. Tal fenômeno tem provocado debates sobre o
currículo da História ensinada de forma que possa construir materiais didáticos,
rituais comemorativos e práticas curriculares na perspectiva da justiça e dos
direitos humanos.

Como os autores apontam, o currículo de História é central, pois expressa conflitos dentro e fora da escola sobre memórias, verdade, legitimidade, identidades representatividade e reparação. Se o conteúdo a ser ensinado está em disputa, qual seria o sentido, o objetivo de ensinar História? O trabalho com os temas sensíveis expressa disputas sobre quais os sentidos legítimos para ensinar História: a continuidade de uma história dos grandes homens e heróis nacionais, curvada ao 
nacionalismo do Estado, espírito com o qual a disciplina escolar foi criada no século XIX, ou uma concepção renovada na qual a formação cidadã seja voltada para o fortalecimento da democracia e respeito à diferença?

Albuquerque Jr. (2016, p. 40) nos oferece uma indicação:

Se ensinar é marcar, se ensinar História é produzir marcas temporais, é discutir e fazer ver as marcas que o tempo deixa em nossos corpos, em nossas vidas e nas nossas sociedades, o ensino da História deve ser capaz de expor feridas, de remexer traumas, de expor a carne sangrando, os corpos em sofrimento, os homens em comoção. Não podemos continuar produzindo gente insensível à dor do outro, gente incapaz de se colocar no lugar e no tempo do outro, incapazes de imaginar e sentir a dor lancinante da perda de um ente amado. Se a escola é o lugar de produção de subjetividades, é o lugar da produção de humanos. Que humanos queremos produzir?, deve ser a pergunta principal.

A educação, em geral, e o ensino de História, especificamente, devem produzir marcas nos sujeitos, como sugere Albuquerque Jr. (2016), ao propor experiências de descentramento de si e aprendizagem com o outro e com o mundo, conforme propomos no início desse texto. Experiências essas em que o "outro" é sujeito incontornável e em que processos históricos permeados pela violência causem desconforto, comoção e sensibilidade nos estudantes. Ou seja, evidencia a necessidade de promoção de uma educação em direitos humanos nas escolas.

A escola forma/produz/fabrica sujeitos e, portanto, forma/produz/fabrica subjetividades. O papel da escola é também acolher essas subjetividades e animá-las, e não as marginalizar, o que afasta os estudantes, que passam a não se reconhecer, não se identificar com esse espaço. Ao fazer emergir outros sujeitos, histórias e memórias na disciplina História, anteriormente apagados, mas vivificados pelo presente, os temas sensíveis possibilitam o seu (re)conhecimento em outras histórias, como nos dizem Pereira e Seffner (2018, p. 20):

As questões sensíveis nos deslocam e nos colocam no lugar de alguém que pensa o presente ao mesmo tempo que pensa o passado, ou pensa o passado ao mesmo tempo que pensa o presente. São questões que nos levam a discutir o problema das identidades, o problema das subjetividades; são questões que nos levam a discutir o pertencimento e a necessidade que os jovens têm de se reconhecer numa história determinada ou em histórias determinadas; de olhar para si mesmos e se autoafirmarem.

A reflexão apresentada acima pelos autores nos parece dialogar com o proposto por Agamben na seção acima: só há possibilidade de ser "contemporâneo" se há um distanciamento e deslocamento de sua própria temporalidade, de forma a compreendê-la em sua "obscuridade", em seus pontos menos visíveis. O trabalho com os temas sensíveis tem a potencialidade em desestabilizar temporalidades lineares ao dialogar com os "passados vivos" - a remanescência do passado que insiste em se fazer presente - que marcam os corpos e identidades de nossos estudantes, ressignificando o presente vivido, possibilitando pensar novos "[...] horizontes de expectativa" (KOSELLECK, 2006).

Dessa maneira podemos encontrar um ponto de fuga dos discursos obscurantistas que tem assolado a sociedade brasileira ao desconsiderar o conhecimento histórico, inserindo no debate público narrativas negacionistas sobre a história, tais como o desprezo pela carga traumática da escravidão e do racismo no Brasil. A partir dessas considerações, apresentamos a seguir trechos de 
entrevistas com professores de História ${ }^{4}$ que atuam na região metropolitana do Rio de Janeiro sobre os desafios e as estratégias de enfrentamento de discursos revisionistas e negacionistas sobre temas sensíveis, sendo parte do material empírico produzido em uma pesquisa de dissertação de mestrado. (PIUBEL, 2020) ${ }^{5}$

Em um contexto de adversidade e questionamento da docência, os professores resistem à essas narrativas negacionistas e excludentes a partir de diferentes estratégias, seja através da produção de conhecimento histórico escolar, do afeto e/ou do diálogo. A seguir apresentamos as narrativas dos professores Catarina e Leandro sobre suas práticas docentes:

Entrevistadora: Tem algum material que você utiliza nessa perspectiva de combater essas narrativas racistas?

Catarina: Eu utilizo muito filme, tem vários filmes que eu gosto muito de passar para eles, principalmente, claro, eu vou pela faixa etária. [...] Esse ano a gente passou Estrelas Além do Tempo para o Ensino Médio, eles amaram e eles fizeram um trabalho de pesquisa e um seminário sobre... [...] eu e a professora de Biologia, a gente trabalhou o papel social da mulher negra na sociedade americana [...]. Mas de novo, no horário de aula, dentro da sala, valendo ponto, valendo nota, avaliação, aí eles reconhecem a seriedade, param e prestam atenção no que eles estão fazendo. (PIUBEL, 2020, p. 77-78)

A professora Catarina se utiliza da cultura midiática dos estudantes, uma produção hollywoodiana, para propor atividades em que os estudantes produzam narrativas outras sobre a experiência da população negra, no caso o papel social da mulher negra estadunidense, desconstruindo visões estereotipadas e histórias únicas sobre esses sujeitos, possibilitando emergir novos (re)conhecimentos.

É sinal que, primeiro, [...], se a gente se dispõe a conversar com um mínimo de pé de igualdade com os alunos, a gente cria questões de identidade, questões comuns, a gente cria um laço e dois, que não exclui o primeiro, valorizar o que o que eles têm a dizer, por mais que seja algo arraigado como racismo, como a misoginia, como LGBTfobia, enfim, com todos os preconceitos do mundo. A gente tem que ter consciência de que são pessoas em formação, qualquer um de nós estamos em formação e acessando as informações que estavam disponíveis para eles. Uma coisa é eu chegar e fazer como o pessoal da internet faz, "eu vou cancelar essa pessoa", a outra é falar assim "não é bem isso, vamos parar para conversar sobre isso? (PIUBEL, 2020)

O professor Leandro apresenta em sua fala a questão do diálogo enquanto estratégia para "desarmar" os estudantes nas disputas de narrativas e visões preconceituosas presentes na sala de aula sobre determinas temáticas sensíveis que atravessam o ensino de História, em uma perspectiva de formar a partir do afeto, entendido enquanto experiência que marca os sujeitos, transformandoos.

A compreensão sobre as identidades, referências culturais, vivências e subjetividades dos estudantes permite aos professores dialogar sobre questões contemporâneas tais como os

\footnotetext{
${ }^{4}$ Os nomes dos professores citados são fictícios. A pesquisa foi aprovada no Comitê de Ética em Pesquisa do Centro de Filosofia e Ciências Humanas da UFRJ, conforme Parecer n. 3.834.960.

${ }^{5}$ Esta pesquisa tinha por objetivo investigar a relação dos professores com os saberes ensinados tendo por foco temas sensíveis. Um dos critérios de seleção para os professores de História entrevistados foi a conclusão do Mestrado Profissional em Ensino de História, conhecido como ProfHistória. Com isso buscamos ressaltar e valorizar a importância da formação continuada de professores.
} 
preconceitos perpetrados e vivenciados no cotidiano. A compreensão de sua própria historicidade, articulada ao conhecimento histórico, possibilita uma relação outra com o tempo, descentrada, mas não deslocada do contemporâneo.

Os discursos conservadores e de extrema-direita que se infiltraram no debate público se confrontam com aqueles do campo historiográfico, dos docentes e dos movimentos sociais progressistas ao reivindicar para si nomear quais heróis, sujeitos, histórias e memórias são legítimas em ser narradas e representativas da história do país e quais devem ser (novamente) apagadas, sem espaço para reinvindicação de direitos.

Em acordo com Eugenio (2018, p. 17), nos parece que, em contextos de instabilidade política e social, os temas sensíveis emergem com mais força, sendo as narrativas escolares, científicas e historiográficas contestadas com mais intensidade nos espaços políticos e nas mídias. No caso do Brasil, temos observado nos espaços públicos e privados uma série de discursos de ódio em relação a questões étnico-raciais, de gênero, de classe e políticas que se fortaleceram no contexto eleitoral, os quais buscaram desconstruir uma série de lutas e políticas públicas voltadas para a igualdade de condições entre os sujeitos.

Nessa guerra de narrativas, que, sem dúvidas, é atravessada pelo campo do político, nos cabe produzir, enquanto professores e pesquisadores do campo da História e do ensino de História, narrativas históricas plenas de sentidos, saberes e sujeitos, com as quais os estudantes da educação básica possam se reconhecer e se autoafirmar, reivindicando um presente menos excludente.

Portanto, nossa defesa vai no sentido de que inserir sujeitos africanos, afro-brasileiros e indígenas e suas histórias na escola, em toda sua dor, resistência e potencialidades - tal qual a Lei n. 11.645/08 determina há mais de 10 anos - é buscar construir uma educação verdadeiramente democrática, na qual a diferença seja constitutiva. E na construção de uma educação democrática os professores têm um papel fundamental, ao produzir narrativas que evidenciem as zonas obscuras do contemporâneo, em seus desafios, contradições, silenciamentos e resistências. Que a História - na figura de seus professores e pesquisadores - possa cantar e contar, cada vez mais intensamente, "[...] a história que a história não conta, o avesso do mesmo lugar"”.

\section{CONSIDERAÇÕES FINAIS}

Os desafios para ensinar e pesquisar História no tempo presente estão postos dentro e fora das escolas: currículos, diferença, negacionismos, educação online, violências, disputas narrativas, ataques aos professores, desvalorização profissional...

Ainda assim, tais aspectos, muitas vezes adversos e frutos de embates, não deixam de evidenciar uma questão fundamental: Qual a importância de ensinar e aprender História hoje?

Buscamos apresentar ao longo do texto a potência da disciplina História em desestabilizar sentidos hegemônicos sobre o mundo e seus sujeitos, a partir de narrativas históricas que animam o passado, possibilitando ressignificar o presente e suas experiências.

Narrativas históricas essas as quais os professores têm papel fundamental em produzir, se contrapondo aos currículos prescritos que, por vezes, reverberam silêncios e esvaziamentos de sujeitos, saberes e práticas no passado e no presente. Nesse sentido, consideramos que a análise proposta neste artigo expressa o entendimento de que, mesmo com os silêncios dos currículos prescritos sobre temáticas do ensino de História que consideramos centrais de ser trabalhadas, tais como o racismo no Brasil, os professores de História subvertem tais silêncios ao traçar estratégias ${ }^{6}$ Referência ao samba enredo História para ninar gente grande (2019), do Grupo Recreativo Escola de Samba Estação
Primeira de Mangueira. 
de produção do conhecimento histórico escolar em uma perspectiva plural, dialógica e que considera as questões do contemporâneo em sala de aula.

Em um contexto em que o currículo prescrito à nível nacional busca reduzir a ideia de "comum" à "homogeneidade", buscamos defender que a diferença, em toda a sua pluralidade e potencialidade, que já se faz presente nas salas de aula, no rosto de cada um de nossos estudantes, seja presença nos currículos, considerando as subjetividades, as vivências e as demandas dos sujeitos envolvidos no processo educacional.

O ensino de História possibilita aos professores e estudantes ser efetivamente "contemporâneos", ao compreender as marcas do tempo nos sujeitos e nas sociedades, marcas essas de dor e violência, mas que ao tornar o passado plural de vozes, tornam também possível pensar o futuro como pluralidade ${ }^{7}$.

\section{REFERÊNCIAS}

AGAMBEN, Giorgio. O que é o contemporâneo? e outros ensaios. Chapecó: Argos Ed. UNOCHAPECÓ, 2009.

ALBUQUERQUE JR., Durval Muniz de. Fazer defeitos nas memórias: para que servem o ensino e a escrita da história? In: GONÇALVES, Márcia de Almeida; ROCHA, Helenice; RESNIK, Luís; MONTEIRO, Ana Maria Ferreira da Costa (orgs.) Qual o valor da história hoje? Rio de Janeiro: FGV Editora, 2012. p. 21-39.

ALBUQUERQUE JR., Durval Muniz de. Regimes de historicidade: como se alimentar de narrativas temporais através do ensino de História. In: MONTEIRO, Ana Maria Ferreira da Costa; GABRIEL, Carmen Teresa; MARTINS, Marcus Leonardo Bomfim (orgs.). Narrativas do Rio de Janeiro em aulas de História. Rio de Janeiro: Mauad X, 2016. p. 21-42.

BALL, Stephen J.; BOWE, Richard; GOLD, Anne. Reforming education and changing schools: case studies in policy sociology. London; New York: Routledge, Taylor \& Francis Group, 1992.

BIESTA, Gertz. Para além da aprendizagem. Educação democrática para um futuro humano. Belo Horizonte: Autêntica, 2013.

EUGENIO, Jonas Camargo. Travessias: histórias de migrantes no ensino de temas sensíveis. 2018. 114f. Dissertação (Mestrado em Ensino de História) - Faculdade de Educação, Universidade Federal do Rio Grande do Sul, Porto Alegre, 2018.

FOUCAULT, Michel. A arqueologia do saber. 6. ed. Rio de Janeiro: Forense, 2000.

GIL, Carmen Zeli de Vargas; EUGENIO, Jonas Camargo. Ensino de história e temas sensíveis: abordagens teórico-metodológicas. Revista História Hoje, v. 7, n. 13, p. 139-159, 2018.

GUIMARÃES, Manoel Luiz Salgado. Nação e civilização nos trópicos: o Instituto Histórico e Geográfico Brasileiro e o Projeto de uma História Nacional. Estudos Históricos, Caminhos da Historiografia, Rio de Janeiro, n. 1, p. 5-27, 1988.

KOSELLECK, Reinhart. Futuro passado. Contribuição à semântica dos tempos históricos. Rio de Janeiro: Contraponto Ed. PUC-Rio, 2006.

MACEDO, Elizabeth. Currículo como espaço-tempo de fronteira cultural. Revista Brasileira de Educação [online], v. 11, n. 32, p. 285-296, 2006.

\footnotetext{
${ }^{7}$ A ideia de pluralidade de futuros da qual nos apropriamos está embasada na seguinte frase do livro Os filhos do barro, do poeta mexicano Octavio Paz: "Nosso futuro, nossa ideia do futuro, balança e vacila: a pluralidade de passados torna plausível a pluralidade de futuros."
} 
MATOS, Júlia Silveira. A História nos livros didáticos: o papel das políticas governamentais na produção e veiculação do saber histórico. Historia, Rio Grande, v. 3, n. 1, p. 51-74, 2012.

MONTEIRO, Ana Maria Ferreira da Costa. Professores de História: entre saberes e práticas. Rio de Janeiro: Mauad, 2007a. 262 p.

MONTEIRO, Ana Maria Ferreira da Costa. Ensino de História: lugar de fronteira. In: Simpósio Nacional de História. Anais... Londrina: Associação Nacional de História, 2007. p. 71-97.

MONTEIRO, Ana Maria Ferreira da Costa; PENNA, Fernando de Araujo. Ensino de História: saberes em lugar de fronteira. Educação \& Realidade, Porto Alegre, v. 36, n. 1, p. 191-211, jan./abr. 2011.

MONTEIRO, Ana Maria Ferreira da Costa. Aulas de História: questões no/do tempo presente. Educar em Revista, Curitiba, n. 58, out./dez. 2015, p. 165-182.

PARAÍSO, Marlucy Alves. Diferença no currículo. Cadernos de Pesquisa, v. 40, n. 140, p. 587-604, maio/ago. 2010.

PEREIRA, Nilton Mullet; SEFFNER, Fernando. Ensino de História: passados vivos e educação em questões sensíveis. Revista História Hoje, v. 7, n. 13, p. 14-33, 2018.

PIUBEL, Thays Merolla. Regimes de verdade e temas sensiveis: currículos e professores de história tensionados nas disputas sobre o racismo. 120f. Rio de Janeiro, 2020. Dissertação (Mestrado em Educação) - Faculdade de Educação, Universidade Federal do Rio de Janeiro, Rio de Janeiro, 2020. RIO DE JANEIRO. Secretaria de Estado de Educação. Currículo mínimo: História. Rio de Janeiro, 2012.18p.

\section{Informações das autoras}

Ana Maria Ferreira da Costa Monteiro

Faculdade de Educação. Universidade Federal do Rio de Janeiro.

E-mail: anammonteiro22@gmail.com

ORCID: https://orcid.org/0000-0002-8114-3198

Link Lattes: http://lattes.cnpq.br/6098382779643532

Thays Merolla Piubel

Programa de Pós-Graduação em Educação. Faculdade de Educação. Universidade Federal do Rio de Janeiro.

E-mail: thaysmerolla@yahoo.com.br

ORCID: https://orcid.org/0000-0003-3166-0223

Link Lattes: http://lattes.cnpq.br/2156254324743675 